\title{
Extracurricular Education and Experimental Course Using Electric Vehicles
}

\author{
Haruo Sakamoto \\ Dept. of Intelligent Mech. Sys. Engr. \\ Kochi University of Technology \\ Tosayamada-cho, Kochi 782, Japan \\ Email: hsk@mech.koch-tech..ac.jp
}

\begin{abstract}
This paper describes an attempt of engineering education in extracurricular activities outside of class and an experimental course in class using electric vehicles. The Kochi University of Technology was inaugurated in April, 1997. Four years of engineering education trials are reported. In 1997, 5 student teams participated in an eco-power race held in Kochi, Japan, with hand-made ecological vehicles. In the summer, 1998, three teams challenged to participate in the Shikoku Electric Vehicle Rally using light-weight vehicles converted into electric cars. Using such light-weight electric vehicles, a student experimental course in class was conducted in the winter, 1998. This paper reports these engineering education activities. In order to provide such an active learning opportunity, a learning environment is needed rather than just teaching in classes. Education on manufacturing is considered to be of great importance as well as the basic sciences such as mathematics and physics.
\end{abstract}

\section{INTRODUCTION}

In Japan, the engineering education system in universities has changed from general cultural courses in the preliminary periods of the 1 st and 2 nd years to ones mixed with engineering science and design courses in the same years. However, the basic idea of education has still been based on fundamental courses in the 1st and 2nd years. Professional courses follow in the $3^{\text {rd }}$ and $4^{\text {th }}$ years. Most fundamental courses seem boring for engineering students since the courses do not relate to real technology. If students have an opportunity to observe the real engineering world in their early years of university life, it is expected that they will more realistically understand engineering science and design courses.

The Kochi University of Technology was opened in April, 1997. The univesity has been trying a new engineering education such as first year seminars using real products ${ }^{1}$, computer assisted English education ${ }^{233)}, 3^{\text {rd }}$ and $4^{\text {th }}$ years' synthetic education, and so on. In this report, engineering education in extracurricular activities out of class and an experimental course in class using electric vehicles are described.

Two extracurricular activities were conducted. The first one is the Eco-power Race. In November, 1997, the Kochi Eco-power Race organized by Toyota Vista Kochi was held in Kochi, and five teams from the Kochi University of Technology entered the race. The second is the Electric Vehicle Rally. In August, 1998, the Shikoku Electric Vehicle Rally, organized by a committee of high school teachers and university faculties, was conducted in Shikoku, the smallest main island in Japan. The rally is the first one in Japan for a car rally on public roads. Three teams from the Kochi University of Technology challenged to join the race. The same rally was held in 2000, in Kochi, and 2 teams from Kochi University of Technology joined. In the winter of the 1998 financial year, the experimental course in class started for $2^{\text {nd }}$ year students. In experiments of material strength, strain gage and accelerator measurements were performed using the electric vehicles. In the following section, these educational activities and course are reported.

\section{EXTRACURRICULAR ACTIVITIES (OUT OF CLASS)}

Extracurricular activities, herein, mean the student activities out of class, and the credit is not given for the activities. Therefore, this does not relate to so-called first year design or capstone design conducted in class in the USA.

\section{Kochi Eco-power Race in 1997}

Each November, the Kochi Eco-power race is held. In the race, hand-made small vehicles compete in a manner similar to small gasoline-powered car racing. The aim is based on both ecological and economical standpoints. In Japan, the Suzuka race by Honda or the mileage marathon race by Shell Oil are famous as small gasolinepowered car racing. Although the Kochi Eco-power Race is local, more than $50 \%$ of the vehicles are from outside of Shikoku, one of the four main islands.

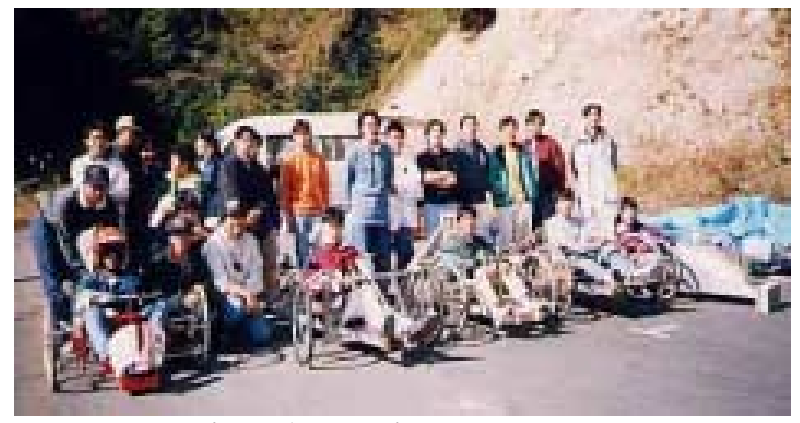

Figure 1 Kochi Eco-power Race

The Kochi University of Technology started in 1997. While there was no experience and no information on how to make such vehicles at that time, five groups of $1^{\text {st }}$ year students participated in the race 
as shown in Figure 1. One of them (left of Figure 1) is the one that one student from Kochi University and people in the community have been devoted to produce for a couple of years. The other one (right of Figure 1) is the team that joined in the race using a vehicle made by Toyota Vista Kochi. Excluding these two teams, the left three teams are the ones that students newly produced the vehicles. One vehicle is gasoline-engine powered and two are battery-powered electric vehicles. The faculty supported them by providing tools, the purchase of motors and parts, and preparing an assembly room. The first one among hand-made vehicles is gasoline-powered one as shown in Figure 2. Figures 3 and 4 shows the small-size electric vehicles. An inwheel motor of $800 \mathrm{~W}$ made by Honda and $412 \mathrm{~V}$ batteries were used.

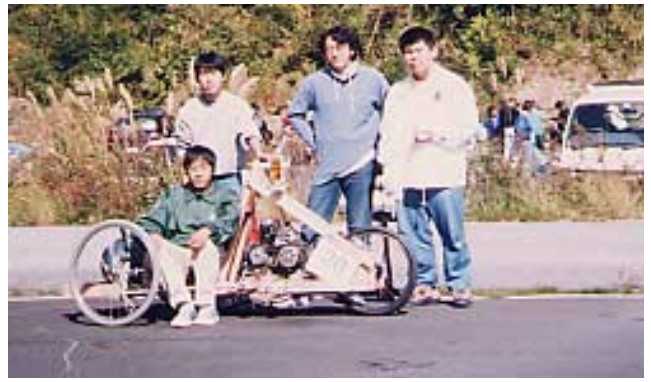

Figure 2 Gasoline-powered Vehicle

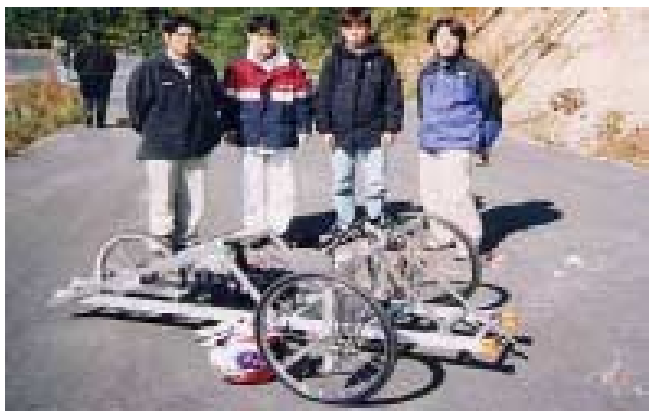

Figure3 Electric Vehicle No.1

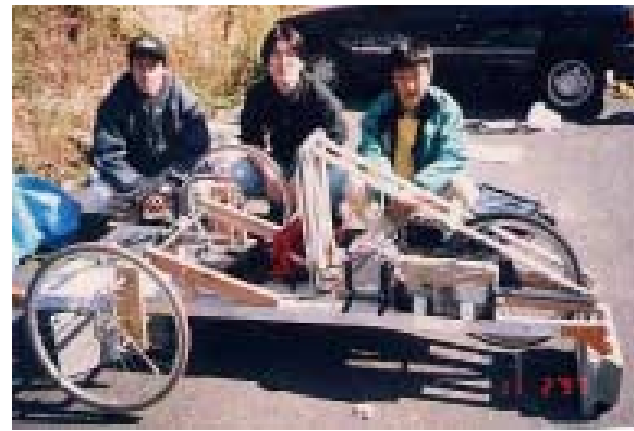

Figure 4 Electric Vehicle No.2

One gasoline-powered vehicle frame was completed in the morning of 5:30am on the day of the race. The engine, however, did not work at that time. After the race started at 9:00am, some engineers who often joined the race kindly helped to fix the engine. The engine did start to work at around 11:00am. The vehicle was able to join the morning session at $12: 00 \mathrm{pm}$ as the last vehicle in the race. It made 11 circuit runs of the 24 required. The gasoline was exhausted by the eleventh run. The second run in the afternoon was conducted by adding gasoline after it had been consumed. The record was $28.5 \mathrm{~km} / \mathrm{l}$, and was the lowest among all the teams to participate. However, they finally succeeded in completing the race. Such a success story will be desired in order for students to learn how to design and manufacture.

On the other hand, the electric vehicles No.1 and No.2 were manufactured, and participated in the race. No.1 and No.2 vehicles succeeded in showing the performance in the demonstration run, which was conducted after the race. However, No.1 seemed to be heavy due to all steel components. No.2 was lighter than No.1, because they used some woods. However, after the race the steering component was deformed, and needed to repair. Two electric vehicles succeeded in the run, and the students experienced to produce a product.

\section{Shikoku Electric Vehicle Rally in 1998}

In the summer, 1998, the Shikoku Electric Vehicle Rally was held, which is the first rally conducted on public roads in Japan. At the Kochi University of Technology, three student teams decided to participate in the rally. Some students joined based on their experience at the Kochi Eco-Power Race in 1997, and some students newly joined. Faculty' support consisted of purchasing the motor and motorcontroller, providing a room for conversion work, and help of obtaining financial aids from private companies. The batteries were supplied through the organizing committee of the Shikoku Electric Vehicle Rally, which is composed of high school teachers and university faculties. The three teams obtained their own used lightweight vehicles with a dealer' help.

The students started to plan the conversion work in April, 1998. However, due to the courses they took, they were not able to really start the conversion work until the batteries were delivered in mid July. For one month prior to the start of the rally in August, they worked, which included the paperwork for the car license. In the last week before the rally started, the first team brought the car to the license office, but it failed to pass. They needed 5 days to pass, and obtained their licenses on Friday. The second team brought the car on Wednesday and obtained the license on the next day. The third team brought their car on Thursday and obtained the license on the same day. They all obtained licenses during the last week before the rally started.

Figure 5 shows our first and second vehicles which are about to start the rally on Monday in the next week after they obtained their licenses. They joined the rally in the second stage in Tokushima, east of Shikoku.

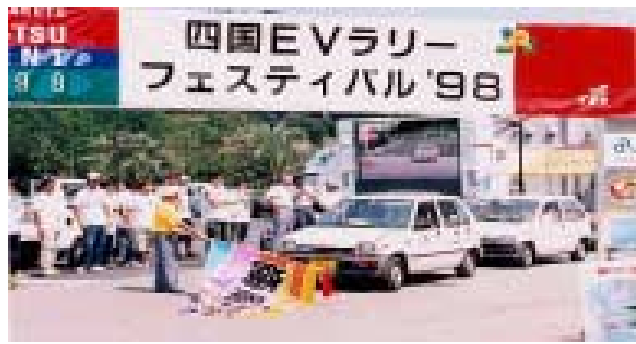

Figure 5 Start of Electric Vehicle Rally

Three teams started the rally, and they succeeded in running up to the final goal. During the rally, the first team shown in Figure 6 was not able to smoothly run at the beginning of the rally, and they needed 
to buy a fuse for the motor-controller. The second and third teams shown in Figures 7 and 8 were able to run. However, they needed to carefully charge at night. The supporters were not able to sleep on beds, and some members slept in the concrete area used for charging. Figure 9 shows the charging. However, they completed the three-days rally from the north of Shikoku to the south of Shikoku, Kochi. This event was a successful experience for the students who joined the rally. This kind of planning and manufacturing will make the students realize how things are done in the real world.. Figure 10 shows the goal of the light-weight vehicle converted into electric vehicle, Team A, No.31.

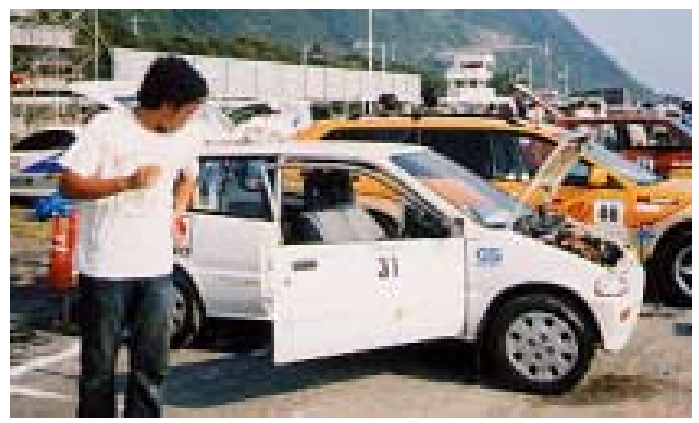

Figure 6 Team A ( No.31)

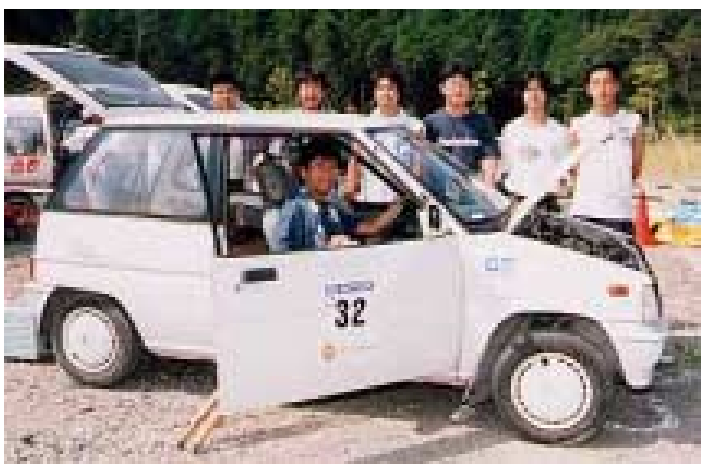

Figure 7 Team B (No.32)

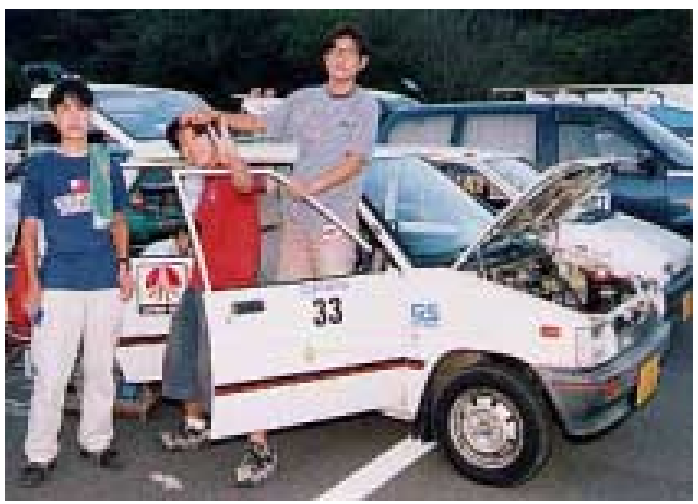

Figure 8 Team C (No.33)

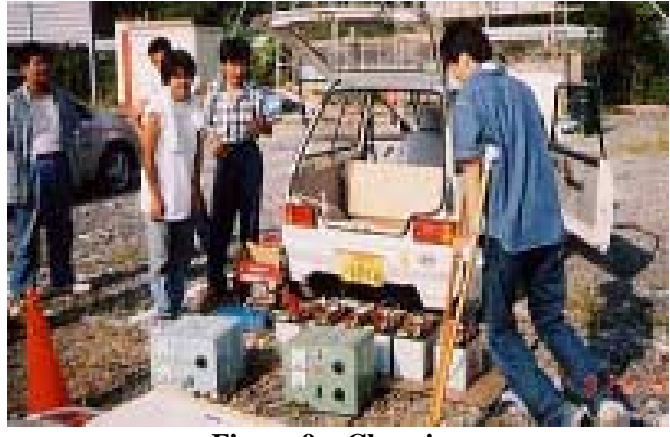

Figure 9 Charging

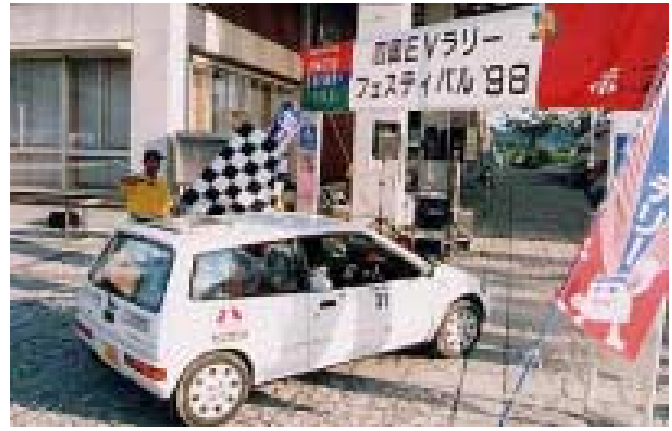

Figure 10 Goal of the Electric Vehicle, No.31

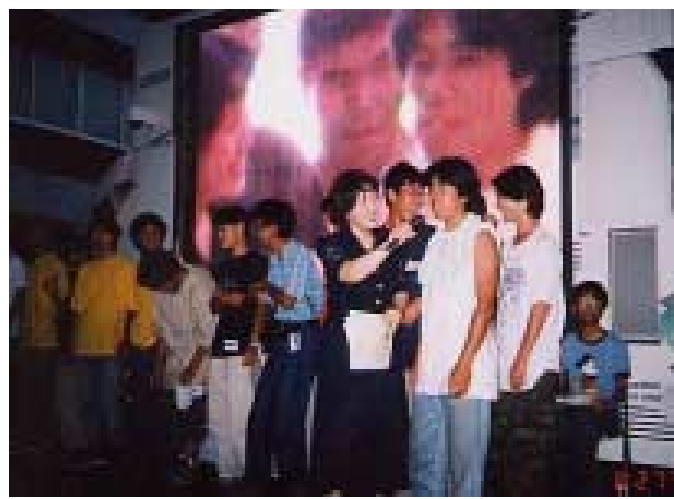

Figure 11 Interview at the Farewell Party

Figure 11 shows the scene of the interview that the students of Kochi University of Technology were asked by to mention an impression of the first rally participation.

\section{International Exchange}

The Kochi University of Technology has a relationship with MIT as brother and sister universities. The Solar-car team of MIT joined the rally, and they came to Kochi to exchange their student activities in the field of electric and solar vehicles. Figure 12 shows the exchange view. MIT team also visited Taisho-town, which is located in the east of Kochi. They exchanged with high school students in the Shimanto Senior High School as an international exchange. Figure 13 shows the scene. 


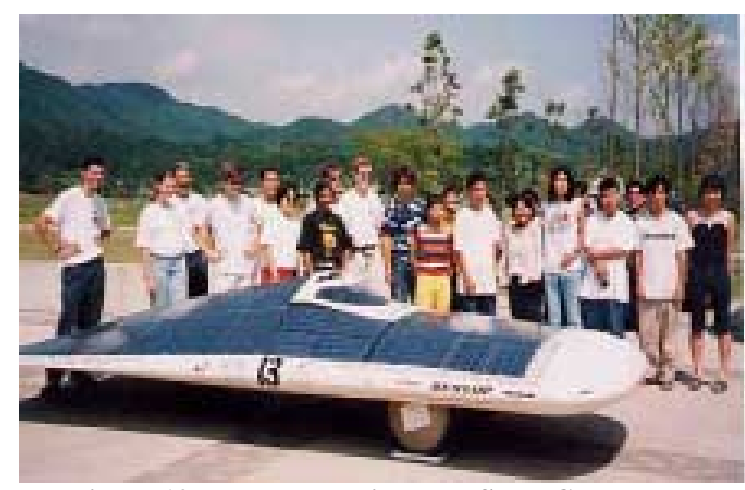

Figure 12 Exchange with MIT Solar Car Team

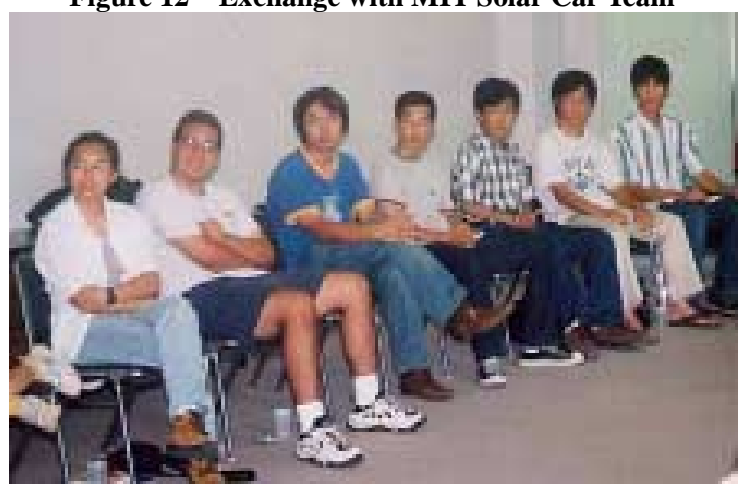

Figure 13 Exchange in Taisho-Town

\section{Service to the Community}

Engineering requires the service to the community, and so the engineering education. The teams had chances to visit elementary schools to demonstrate their electric vehicles to children. Figure 14 shows the electric vehicle seminar held in Kusume Elementary School near the university, and Figure 15 shows the solar-car kit assembly seminar conducted in the municipal house in Taisho-town. In case of elementary schools such as Kusume Elementary School, the students planned the seminar by themselves, and discussed with teachers of elementary schools without any faculty' interference. Such a chance of planning the community service will lead students to become independent of teachers or faculties

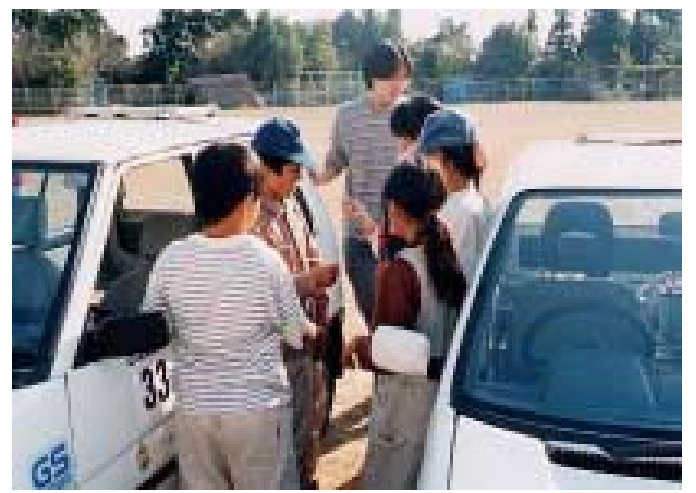

Figure 14 Electric Vehicle Seminar in Kusume Elementary School

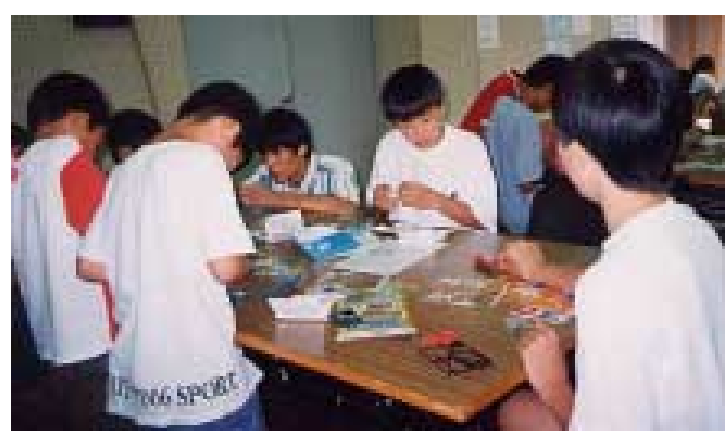

Figure 15 Solar-car Kit Assembly Seminar in Taisho-town

\section{Shikoku Electric Vehicle Rally in 2000}

In the summer, 2000, the Shikoku Electric Vehicle Rally was held in Kochi, Shikoku. The participants were 50 vehicles and 200 people. The rally was successful. From the Kochi University of Technology two teams participated. One is the same as the one in 1998, shown in Figure 16. The other is the one converted from the medium size vehicle into electric vehicle. The records of the two vehicles were not good enough. However, they were able to complete to the end of the rally.

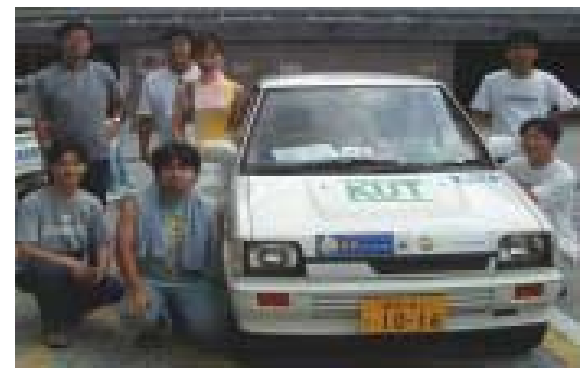

Figure 16 Light-weight Electric Vehicle, 2000

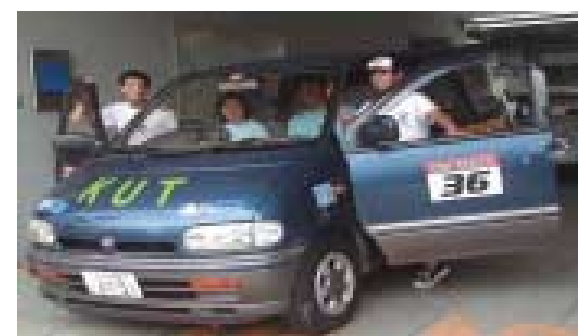

Figure 17 Medium-size Electric Vehicle, 2000

\section{EXPERIMENTAL COURSE (IN CLASS) ON THE STRENGTH OF MATERIALS}

In the second year of the mechanical engineering department, in 1998, students take an experimental course. It consists of 5 subjects, fluid dynamics, mechanical vibration, control, thermal dynamics, and material strength. The author contributes to the strength of material in the student's experimental course. The basic learning item is how to use strain gages and accelerator sensors. First, the students learn how to attach these gages and sensors on an aluminum plate. Figure 18 shows a scene for students learning to do such a basic setup.

As a second step, they are required to plan what and how strain and acceleration are measured in a vehicle. The instructor, the author, 
does not tell them what should be measured and how to do it. They need to plan as if they are automotive engineers. After the planning, they prepare the measurement. They needed attaching gages and accelerators to the vehicle they are given and wiring to the recorder. Figure 19 is a scene of the preparation. Before the preparation, safety issues such as watching high electric current and rotational parts were confirmed.

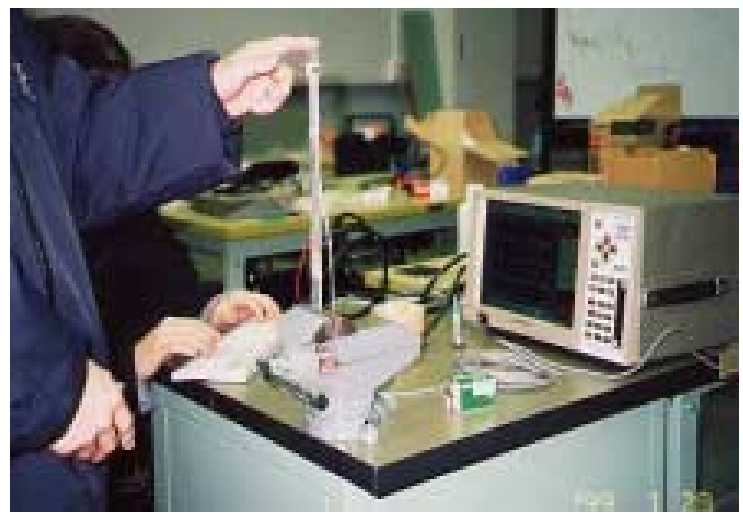

Figure 18 Measurement of Strain and Acceleration on Aluminum Plate

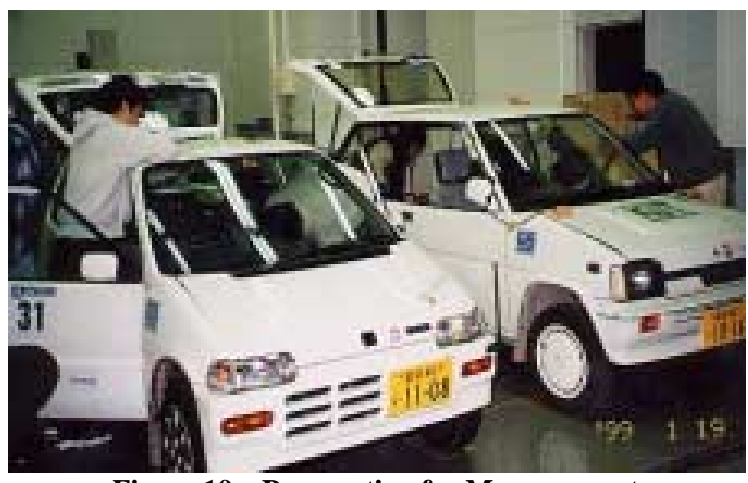

Figure 19 Preparation for Measurement

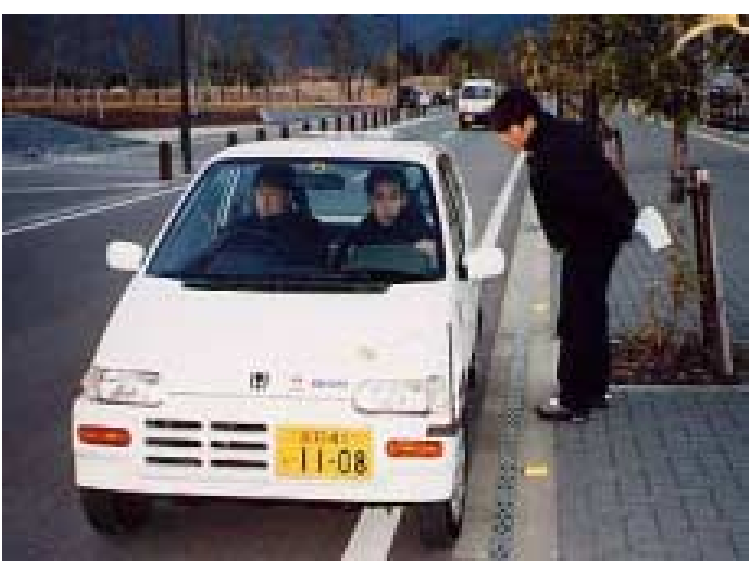

Figure 20 Running the Measurement Test

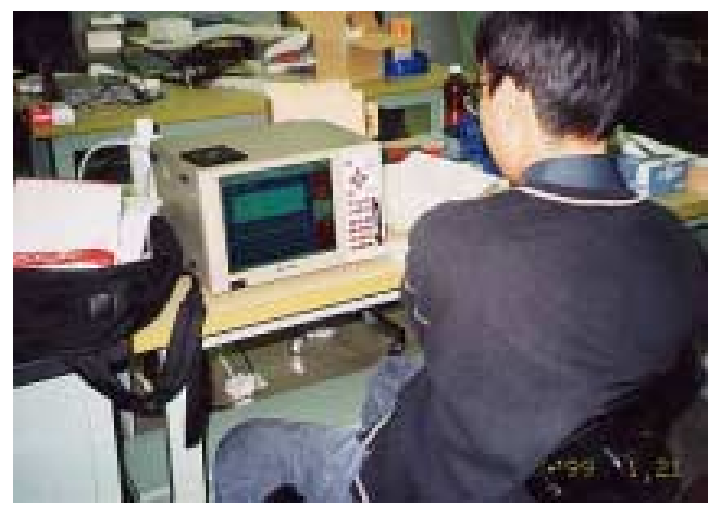

Figure 21 Analysis of Measured Data

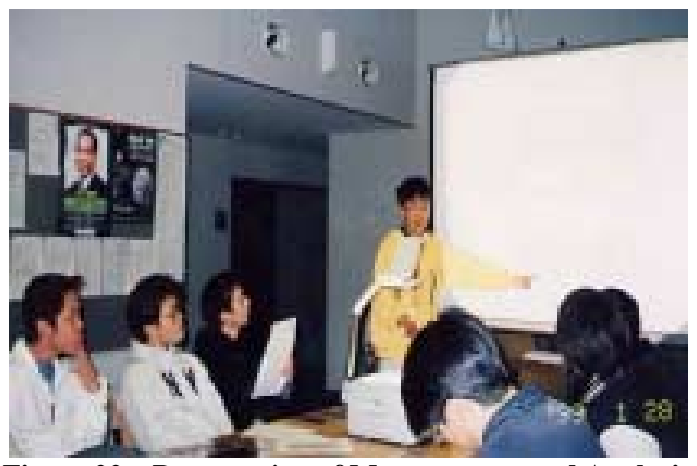

Figure 22 Presentation of Measurement and Analysis

\section{Paved Road' '30Km/h Vibratin}

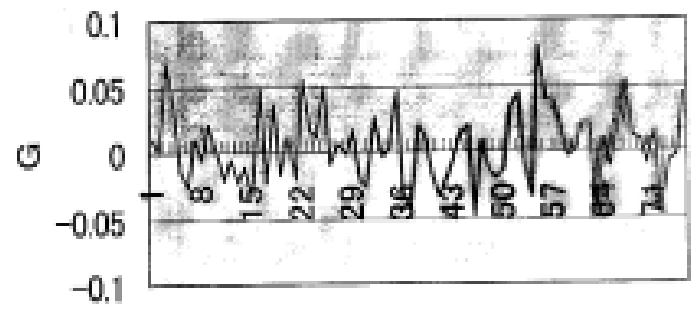

Figure 23 Data Example

After the preparation was finished, the running test for the measurement of the items they planned was performed. Figure 20 shows the running test scene. Figures 21,22 , and 23 are the analysis, presentation, and an example of the data they presented. The measurements of each team were aimed at different targets such as the effect of road smoothness on the vibration, strain origination by the brake action, or vibration created when the car goes through a curve. In the 5-days experimental course, they were able to perform the preparation, measurement, analysis, oral presentation, and report making. The data were recorded using a digital recorder and filed in a ATA card. They used a personal computer and Excel software for the analysis that was conducted in a short time. 


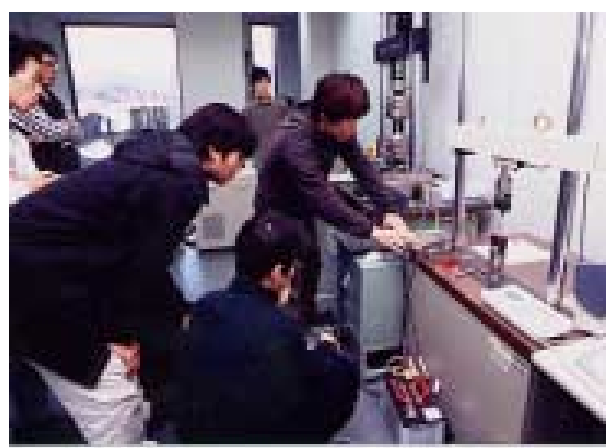

Figure 24 Tensile Test in 1999

During the next year, 1999, the course time was changed from 5 days in 1998 to 2 days in 1999. Two days were not enough to conduct the measurement using vehicles. Instead, the measurement in a car was replaced by the tensile tests shown in Figure 24. Compared with the measurement in a car in 1998, they were just able to learn what the faculty prepared. The measurement in a car requires students to determine what and how they need to measure. In other words, they need to plan their experiment, and, therefore, they need to think and discuss. Planning, thinking, and discussion are considered to be of great importance in such an experimental course than just understanding what the faculty prepares. Studying by thinking and discussing by themselves needs to be taken into account for engineering education. In the early-stage schools up to senior high schools, the education is conducted by almost teaching. In universities, preparing the conditions for students to learn by themselves is desired. Mathematics and physics are considered to be of importance for engineering. However, courses of mathematics and physics and even those of engineering sciences such as fluid dynamics and so on are the ones students need to understand. They do not think in a different way nor create something from such courses. The experimental course can be a candidate so that they can plan, think, and discuss.

\section{CONCLUDING REMARKS}

An attempt of engineering education with extracurricular activities outside of class and an experimental course in class has been conducted at the Kochi University of Technology that opened in 1997. Students joined the Kochi Eco-power Race in 1997 and the Shikoku Electric Vehicle Rally in 1998. Using converted electric vehicles, the experimental course on the strength of material was conducted. The following results were obtained.

1. Manufacturing aroused the students' motivation to do the engineering activities such as making a small vehicle and converting it into an electric vehicle.

2. Students were able to obtain successful results in such activities. Such an experience is considered to provide a successful engineering education.

3. The experimental course in class using real products such as the converted electric vehicles is considered to be a proper curriculum for students to plan, think, and discuss rather than just teaching in classes.

4. In the process from the $1^{\text {st }}$ to $3^{\text {rd }}$ years described in this paper, students planned, conducted, and discussed the activities and the course. Such an educational trial for experience is considered to be highly important as well as the basic sciences such as mathematics and physics. Therefore, engineering education is desired to be half and half of half real word experience such as product dissection or activities reported herein and half basic studies such as mathematics and physics.

5. In the $3^{\text {rd }}$ and $4^{\text {th }}$ years, a different type of education were conducted in a manner that students belong to an individual faculty research laboratory from the $3^{\text {rd }}$ year. The education also stresses on action and thinking.

\section{ACKNOWLEDGEMENT} activities.

The author greatly acknowledges people who let us join their

\section{REFERENCES}

1) Haruo Sakamoto, Kazuhiro Kusukawa, Jens Jorgensen, Mechanical Engineering Education for $1^{\text {st }}$ Year Seminar Using Real Products, ASME, DE-Vol.102, (1999), p13-17.

2) David Greene. "LATCH: a syllabus design for EFL instruction in CALL" in Computer Assisted Language Learning (Lisse, The Netherlands), 11, 4, 381-96.

3)Lawrie Hunter. "Text nouveau: visible structure in text presentation" in Computer Assisted Language Learning (Lisse, The Netherlands), 11, 4, 363-79. 